\title{
Sobre Los Náufragos de Patrick Declerck
}

Hoy, con el fenómeno masivo de la exclusión social, los clínicos y los trabajadores sociales se encuentran atrapados en un vértigo entre medicalizar lo social o «etnologizar» el sufrimiento psíquico. Con la exclusión, la sociedad se forja una imagen del otro radical que ya no es el migrante sino el pobre. Volvemos así a una manera de estigmatizar que era dominante hace unos veinte años, como pudo establecerlo uno de los más inventivos seguidores de G. Balandier, G. Althabe. Desde entonces se produjo el gran éxito mediático, electoral, incluso universitario, de las militancias segregativas y culturalistas, representadas en Francia por la neoetnopsiquiatría de T. Nathan o M.-R. Moro.

Éste más allá de la pobreza que es la miseria lleva a considerar que el sujeto situado «fuera-de-lugar» ya no es entonces única y simplemente el exiliado «exótico», se convierte en el exiliado del interior al que se llama «excluido». Digamos enseguida que la incomodidad de los psicólogos, psiquiatras y trabajadores sociales frente a la exclusión es inevitable, pero la cuestión que la motiva sigue estando mal planteada.

La afirmación de que existe una categoría supuestamente homogénea de excluidos es una ficción; es decir, que no es más que una hipótesis considerada erróneamente como una tesis. Esta reducción ideológica que unifica a los excluidos como población aparte, legitima el hecho de que se preconice cierto número de tratamientos dirigidos a una población concreta. Desde hace unos años, la sociología y la antropología de lo contemporáneo, con y después de Balandier, se han interesado por lo que podría llamarse la estructura negativa de la sociedad: la exclusión. Este interés, con excepción de las investigaciones de Vexliard, que tienen ya cerca de medio siglo, no ha producido muchos documentos clínicos accesibles al gran público. Existen informes de investigación, pero siguen teniendo poca difusión. Hay también actas de coloquios (recientemente, y bajo la dirección de F. de Rivoyre, Psychanalyse et malaise social, editado por Érès), números de revistas (Psychologie clinique, en 1999, L'homme et la société, en 2001, editadas por L'Harmattan), pero hasta ahora disponemos de pocos testimonios de envergadura que se refieran a los modos de tratamiento psíquico posible con sujetos crónicos de la indigencia.

He aquí, pues, que Patrick Declerck, antropólogo y psicoanalista, relata en este volumen de la colección Terre Humaine, su trabajo etnográfico y psicoterapéutico con indigentes [Los náufragos, Madrid, AEN, 2006]. No se trata para él de explicarnos cómo cuidar a los indigentes con vistas a reinsertarlos (pura quimera, la mayoría de las veces) sino de cómo hacerles una vida posible. Y ha querido situarse lo más cerca posible de la vida de los indigentes como antropólogo, guiado y aconsejado por G. Devereux, y luego dialogando con J. Malaurie (el 
director de esta insustituible colección de libros) ${ }^{1}$, amoldándose a los ritmos precisos e inevitables de su vida cotidiana, en esos momentos en que -a menudo por propia voluntad-son recogidos e «higienizados» por los centros de alojamiento de urgencia, entre los cuales se encuentra el C.A.S.H. (Centro de acogida y cuidado hospitalario) de Nanterre.

Antropólogo y psicoanalista, habla de clínica a partir de su consulta de escucha destinada a los indomiciliados, la primera de este tipo en Francia, que abrió en el marco de Médicos del Mundo. Nos da así indicaciones sobre la psicopatología de la extrema desinserción, sin prescindir de las dimensiones transferenciales y contra-transferenciales que han dado peso y sentido a algunos de sus modos de hacerse cargo de ellos.

En un primer momento, veremos cómo su proceder inscribe una ruptura en las tendencias clásicas de la investigación que se refiere al hecho social atípico en antropología. En segundo lugar, designaremos los ejes de la clínica a la cual nos introduce.

Si la tendencia clásica de las investigaciones sociológicas con R. Linton, antropológicas con C. Lévi-Strauss, incluso etnopsicoanalíticas con G. Devereux, ha consistido en las contradicciones de la sociedad y las resoluciones estructurales de esas contradicciones sociales a partir de los sistemas de exclusión, el aumento importante de los excluidos en el mundo occidental, lleva a considerar esta «categoría» de los «excluidos» por sí misma. Más adelantados que nosostros en sus elaboraciones, algunos novelistas ya intentaron acercarse lo más posible a esta condición del sujeto reducido a una pura supervivencia. Aquí se impone la novela de Walter Kolbenhof, Untermenschen, aparecida inicialmente en 1933 en la Trobis, editorial fundada en Copenhague por el psicoanalista comunista alemán en el exilio, W. Reich.

La exclusión, término a la vez demasiado real y demasiado alegórico, supone un individuo que no está, o que ya no está, integrado en una red de solidaridad familiar, amistosa o de barrio. Semejante definición establece, pues, una línea divisoria entre exclusión y precariedad. Existen barrios, suburbios en situación económica precaria pero en los que se producen sistemas y redes de solidaridad económica, basados unas veces en el trueque, otras en economías marginales o poco legales. Debido a la existencia de esas redes de solidaridad, no puede hablarse en esos casos de exclusión. A la inversa, en ciertos islotes de exclusión, no-luga-

La colección Terre humaine, dirigida por Jean Malaurie, es una empresa singular que nació en 1955. Roza ya el centenar de títulos, entre los que se cuentan: Los últimos reyes de Thulé de Malaurie y Tristes trópicos de Lévi-Strauss, Los inmemoriales de Segalen, Praga mágica de Ripellino, Chronique des indiens Guayaki de Clastres, Las venas abiertas de América Latina de Galeano, Ishi de Kroeber, Lo exótico es cotidiano de Condominas, L'été grec de Lacarrière, Carnets indiens de Ribeiro, Terres vivantes de Dumont o una obra tan impresionante como Elogiemos ahora a hombres famosos, de Agee. (N. de la R.) 
res situados en las orillas de lo que muestra y permite el desplazamiento de los cuerpos y de los objetos, de lo que da presencia y hace físicamente palpable la velocidad (ramales conexión de autopistas, halls de estaciones o de aeropuertos), se puede ver cómo se reúnen algunos «encerrados fuera», «exiliados del interior» como se les llama a veces. El excluido ya no es entonces solamente el que vive en los lugares donde reinan la miseria y el paro masivo, es el que ha superado una línea, un umbral, un pasaje, que ha llevado a cabo un salto en el que se ausenta del vínculo social y la fraternidad de discurso.

Es a menudo a través de una relación catastrófica con el espacio común, con la polis, como la precariedad se inclina hacia la exclusión. En París, viven o sobreviven entre 10.000 y 15.000 indigentes; en torno a este núcleo gravita una población heterogénea, compuesta por jóvenes, a veces adolescentes, toxicómanos y prostitutos de ambos sexos, personas perdidas al salir de la cárcel, incluso del hospital psiquiátrico. El mundo de indigencia también evoluciona, y muy deprisa, convirtiéndose sin duda en algo aún más inquietante y violento de lo que era hasta entonces.

P. Declerk no nos presenta solamente los resultados de una observación partícipe fechada. Disfrazado de indigente, hace quince años, se sintió motivado para conocer desde dentro los centros de alojamiento de urgencia. La presencia peligrosa de toxicómanos, la complicación debida al deterioro de la higiene o por la frecuencia de contaminaciones VIH (circulan agujas infectadas) son factores bastante nuevos que, según dice, le disuadieron hace poco de proseguir hasta su término otra observación directa. Las descripciones que nos ofrece de su experiencia «antropológica» pasada son duras, emocionantes, y convierten el principio de este libro en una forma de hazaña de gran periodista. Con lo que pueda haber fascinante e impresionante, incluso heroico en esta forma de proceder. También, y eso puede molestarnos, con un lirismo un poco a lo Céline y casi gozoso a la hora de describir cuerpos, como si la realidad se convirtiera, y se sublimara, en un cuadro de Brueghel padre y el Bosco. De todas formas, un libro constituido por ese tipo de testimonio pronto habría encontrado su límite. Sin embargo, si el título Los náufragos evoca una colección del otro al cabo de la cuerda, y anuncia casi un espectáculo de la radical extrañeza de esas alteridades límite, el subtítulo propuesto «Con los indigentes de París» tranquiliza y es más adecuado. De este «con», sabe hablarnos este libro.

P. Declerck encontró realmente sujetos como «otro» que ellos y como un interlocutor de su miseria y de su humanidad. Había que describir las condiciones de existencia, las crueldades, sin duda poco evitables, de la forma que adoptan algunos auxilios de urgencia, pero el autor va más lejos. No se expone a nosotros únicamente como el que ha compartido las formas de vida y las costumbres de una 
tribu lejana. Indica cómo interviene, oye, habla y se coloca a la altura de las peticiones de escucha que le dirigen. Es un psicoanalista sin diván, que tiene sus convicciones teóricas y sabe dónde está con su compasión, sus arrebatos de ira, algunas veces, sus bruscos deseos de echar a esos clientes o de seguirles, a lo lejos, una vez pasados los muros con esa voluntad patética de localizar los trayectos de vagabundeo, a menudo mortales, que conocieron algunos.

Y vemos cómo esos grandes excluidos llegan a tener densidad humana. En sus melancolizaciones, nos hacen ver que lo que permite a un sujeto darse una consistencia de cuerpo y de lenguaje es que algo de su historia individual en sus desfallecimientos se apoya en la historia colectiva. Vemos muy bien cómo sujetos que se encuentran en gran exclusión traen al primer plano lo que de no compartible y no simbolizable ha reabierto la historia colectiva, ha reabierto en la violencia de nuestra época.

Los excluidos niegan la mayoría de las veces los trayectos de reinserción que se les proponen. Queda destacado bastante dolorosamente que el sentimiento de deuda es bastante poco conocido para ellos, $\mathrm{o}$, al menos, bastante poco motor, con el riesgo de que el cuidado se reduzca a la gestión más apropiada del organismo de cada uno de ellos o de la masa que representan colectivamente. Los excesos de cólera, de los rechazos virulentos o de los odios expresados a veces por sujetos marcados por una vivencia de exclusión han recibido a menudo una explicación comprensiva, compasiva y médica. No es falso cargar tales excesos en la cuenta de las ingestas masivas de alcohol y de disolvente. Pero ¡qué reductor resulta! Ya sería hora también de situar esta agitación del cuerpo propio, esas mostraciones de lo obsceno, esos excesos, esos arrebatos de ira, esos gritos, etc., como signos de resistencia a la violencia soft, civilizada, eficaz que está agobiando nuestros tiempos llamados «modernos». Los sujetos en exclusión y que no (o que ya no) se avienen a esos apaños sociales, manifiestan una manera de resistir a la promoción actual de enmascaramiento de lo real de los cuerpos, de las hablas, de las historias y de los lugares.

Anti cromo y anti manual para almas delicadas llenas de buenos sentimientos y militantes de la caridad y de la compasión todo terreno, este libro, que no le suelta a uno, plantea cuestiones justas y anuncia desilusiones necesarias.

Porque es un investigador consecuente, P. Declerck rechaza el confort aseptizado que destila el uso de ciertas palabras. Como la palabra 'reinserción', que recuerda a la 'sobreinclusión', utilizada de manera crítica por P.-L. Assoun cuando habla del excluido como sujeto del perjuicio. Hay que hacerse a la idea de que muchos hombres y mujeres que sobreviven en los límites de la razón social y de la razón humana, nunca han sido insertados. La urgencia, si es que hay una, no es la de reincluir o re-insertar, sino la de permitir a esos sujetos poder utilizar mejor, 
dice P. Declerck, las funciones de abrigo y de cuidado que ofrecen algunas instituciones. Hay exilios del interior, sin gran retorno posible hacia soluciones sociales convencionales, pero a los que se puede ayudar a no seguir destruyéndose. Programa mínimo, resignado, derrotista dirán algunos. Programa que más bien toma en serio lo que se está destituyendo. Se ve colocada en primer plano la función asilar del cuidado psíquico, actualmente despreciada en provecho de la función promocional del cuidado educativo.

¿Es que hoy en día sólo queda la calle como lugar en el que se pueda estar loco? Es cierto que se ve en la calle (en algunas ocasiones he estado asociado a «búsqueda de clientes» del Samu Social en París, o en otras partes en Bamako) una forma de Hospital psiquiátrico errático y disociado. Ir al encuentro de los grandes excluidos, que no han tardado mucho en hacerse crónicos, lleva a encontrarse con una población en gran parte compuesta por grandes delirantes, a menudo esquizofrénicos de los que nadie se ocupa, salvo en caso de que caigan en estado de incuria, desarrollando enfermedades y afecciones somáticas graves (úlcera, gangrena, etc.), y que se encuentran, debido a la conjunción entre su estructura psicótica y la extrema carencia en la que están macerando, agarrados a su dolor y a sus llagas, como si así se escribiera, aún con riesgo de su vida, la única firma o el único compañero que aún pudiera quedarles.

Con el fin de oponerse a esta presencia devastadora de la muerte como objeto y como proceso en sí, la clínica de los grandes excluidos lleva a tomar en serio esta función de la acogida, del asilo. Lleva a favorecer la creación de una red de acogida, de alojamiento y de cuidados, sin cargar con rebuscados tecnicismos y alta tecnología, ni acreditación sofisticada o evaluación policial, es decir, sin adherirse a esta masa de artilugios presupuestarios y cientifistas que están dejando en nada la Institución de cuidado.

Rechazando igualmente el indigesto pathos en torno al «sufrimiento psíquico» y a la «victimología», P. Declerck está empeñado en hacer valer una tesis, robusta y necesaria: una gestión sana de la cronicidad va acompañada de un abandono de la fascinación por el extranjero y por la víctima. Lo que hay que reconsiderar de cabo a rabo es, pues, el término de exclusión, al menos por las razones siguientes. En primer lugar, fabrica una masificación de categoría: los excluidos sin ninguna pertinencia clínica; en segundo lugar, hace de los «excluidos» una suma de víctima, sin que se llegue a plantear la dimensión del rechazo o de la transgresión que se observa en algunos. La víctima es a la vez objetivada y absuelta. Last but not least, este término, que lo explica todo, no explica nada.

Hay que conocer el libro de P. Declerck, y releerlo. Muy comprometido, le favorece además una construcción muy libre, como una marquetería «free-jazz» en que los testimonios, los recuerdos personales, los edificios teóricos, y los frag- 
mentos autobiográficos se responden y cada uno de ellos conserva su consistencia e insistencia propias. Entre mostración de demostración, este libro propone hipótesis a la clínica y bases de reflexión a la Institución. «Descaridatiza», en el mejor momento de su escritura, con una tierna e incansable ferocidad.

Las almas sensibles, se ha dicho, deberían prohibirse la lectura de este libro, tal vez incluso tuvieran que abstenerse de hacer clínica.

Sin embargo, un libro así ¿estaría ya un tanto pasado? Sí y no. No, pues lo insustituible del testimonio no está destinado a volverse obsoleto. Sí, un poco, lo cual es menos un reproche que una petición de otras contribuciones. En efecto, la actualidad de las instituciones que se hacen cargo de los grandes excluidos está ahora, y gracias a los trabajos de los pioneros, entre los que se encuentran Declerck, Henri y Emmannuelli, y a la creación de redes como la ORSPERE en Lyon o el RNSPP (Red Nacional de Sufrimiento Psíquico y Precariedad), mucho más diversificada y tal vez sea más eficaz también en el sentido de la prevención.

Exclusión, precariedad, vagabundeo y salud mental: se han hecho balances, pero todavía está por hacer un balance de las maneras de actuar en esas instituciones y esas redes que se ocupan de la exclusión. ¿Será ésa la verdadera urgencia?

* Olivier Douville es Psicoanalista y Profesor titular, en París (Francia). Desde hace tiempo es el Director de publicación de la revista Psychologie clinique. Este escrito lo redactó tras la salida del libro de Declerck en Francia (2001): agradecemos a su autor la rápida aceptación de reproducirlo ahora en nuestra Revista. (Traducción de Julián Mateo Ballorca). 